Notrica, F.P. Hay que decir que sí a una regulación de gestación por sustitución. Derecho y Ciencias Sociales. Abril 2018. $\mathrm{N}^{\circ}$ 18. (Las familias y el derecho de las familias a dos años de vigencia del Código Civil y Comercial) Pgs 82-98. ISNN 1852-2971. Instituto de Cultura Jurídica y Maestría en Sociología Jurídica. FCJ y S. UNLP

\title{
Hay que decir que sí a una regulación de gestación por sustitución
}

We have to say yes to a regulation of surrogacy

\section{Federico Pablo Notrica ${ }^{\bullet}$}

\section{Resumen}

El presente trabajo referido a los procedimientos de gestación por sustitución se centra en los argumentos que sirven para posicionarse a favor de la práctica. Los derechos humanos de las personas involucradas dentro del procedimiento, entre ellas, la gestante, los requirentes y el niño o niña que nace deben ser garantizados, desde una mirada constitucional y convencional, razón por la cual, el desarrollo del trabajo se ajusta a distintos principios derivados de los Tratados Internacionales de Derechos Humanos y normativa interna argentina. En este sentido, se analizarán puntos centrales como el derecho a fundar una familia, la voluntad procreacional, el interés superior del niño, el derecho a la identidad, el derecho a la salud sexual y reproductiva, a gozar de los beneficios y avances de la ciencia y la tecnología, el principio de igualdad y no discriminación y la realidad actual y su problemática.

Palabras clave: gestación por sustitución; filiación; técnicas de reproducción

\begin{abstract}
The present work referring to the procedures of gestation by substitution focuses on the arguments that serve to position itself in favour of the practice. The human rights of the persons involved in the procedure, including the pregnant, the purchasers and the child born must be guaranteed, from a constitutional and conventional perspective, which is why the development of the work is adjusted to Different principles derived from international human rights treaties and Argentine internal regulations. In this sense, central points will be analyzed such as the right to found a family, the procreational will, the best interests of the child, the right to identity, the right to sexual and reproductive health, to enjoy the benefits and advances of science and Technology, the principle of equality and non-discrimination and the current reality and its problematic.
\end{abstract}

Key words: surrogacy; filiation; assisted reproductive treatments

\footnotetext{
- Abogado (UBA), Maestrando de la Maestría de Familia, Infancia y Adolescencia (UBA). Docente de Familia y Sucesiones (UBA - UNDAV). Miembro del Proyecto de Investigación UBACyT "Realidad y legalidad: instrumentación, articulación e implementación de las Técnicas de Reproducción Humana Asistida en el Código Civil y Comercial de la Nación.”. Auxiliar letrado de la Cámara de Apelaciones en lo Civil, Comercial y de Familia del Dpto. Judicial Lomas de Zamora. Correo electrónico: fedenotrica@ gmail.com.
} 
Notrica, F.P. Hay que decir que sí a una regulación de gestación por sustitución. Derecho y Ciencias Sociales. Abril 2018. $\mathrm{N}^{\circ}$ 18. (Las familias y el derecho de las familias a dos años de vigencia del Código Civil y Comercial) Pgs 82-98. ISNN 1852-2971. Instituto de Cultura Jurídica y Maestría en Sociología Jurídica. FCJ y S. UNLP

\section{Hay que decir que sí a una regulación de gestación por sustitución}

Federico Pablo Notrica

\section{Introducción}

La gestación por sustitución -en adelante GS- es uno de los temas más debatidos en el derecho de las familias y el campo de la bioética, en virtud de que las sociedades modernas han visto ampliadas las formas de vivir en familia y a la par, las normas no habrían dado una respuesta acorde a estas y otras situaciones complejas (Corral Dueñas, 2003). Estas cuestiones, sin duda, produjeron un encuentro obligado entre bioética y derecho, necesario para estudiar y profundizar sobre las nuevas realidades y composiciones familiares en las que las técnicas de reproducción humana asistida (TRHA) comenzaron a jugar un papel vital y, dentro de este extenso campo, la gestación por sustitución.

Sentado ello, es necesario definir a la GS como una forma de reproducción asistida por medio de la cual una persona, denominada gestante, acuerda con otra, o con una pareja, denominada comitente/s, gestar un embrión con el objetivo de que la persona nacida tenga vínculos jurídicos de filiación con este/os último/s (Lamm, 2012).

La GS, en tanto procedimiento reconocido por la OMS, permite que aquellas personas que quieran formar una familia y no puedan hacerlo por su imposibilidad de gestar y/o llevar a término un embarazo por razones de salud o estructurales, no vean cercenados sus derechos a la paternidad/maternidad, en íntima conexión con el derecho a la vida familiar y el acceso a ella, el derecho a la autonomía y desarrollo personal, el derecho a la salud y el derecho a gozar de los beneficios de los avances científicos, reconocidos por nuestra Constitución Nacional y los tratados internacionales de derechos humanos de rango Constitucional (conforme artículo 75, inciso 22) y por el cual se asevera que "No hay ninguna norma en la Constitución o en los IIDH que inhiba la gestación por sustitución. Al contrario, el principio pro persona expande la gestación por sustitución en base a los derechos a la vida privada y familiar (art. $11 \mathrm{CADH}$ ), a la integridad personal (art. 5.1 CADH), a la libertad personal (art. 7.1 CADH), a la igualdad y a no ser discriminado (art. $24 \mathrm{CADH}$ ) en cuanto al derecho a la maternidad y de conformar una familia, la que juega un papel central conforme art. 17 de la CADH”(Gil Domínguez, 2015:237). 
Notrica, F.P. Hay que decir que sí a una regulación de gestación por sustitución. Derecho y Ciencias Sociales. Abril 2018. $\mathrm{N}^{\circ}$ 18. (Las familias y el derecho de las familias a dos años de vigencia del Código Civil y Comercial) Pgs 82-98. ISNN 1852-2971. Instituto de Cultura Jurídica y Maestría en Sociología Jurídica. FCJ y S. UNLP

Sentado ello, cabe señalarse que en la legislación argentina no existe norma alguna que regule este procedimiento, ni tampoco las consecuencias que se derivan en el campo de la filiación; es más, el art. 562 del Código Civil y Comercial (CCyC) determina que quien da a luz a un niño o niña es progenitor suyo, con lo cual, no habría lugar para ubicar la GS dentro de esta norma. Pero se requiere una que esté en consonancia con los derechos humanos reconocidos por los Tratados Internacionales ratificados por la Argentina a partir de 1994. En virtud de ello, se propone en este trabajo desarrollar los diferentes argumentos que sirven para posicionarse a favor de una regulación acorde con los principios constitucionales convencionales y los derechos humanos de los involucrados.

\section{Los argumentos a favor de la GS}

\section{a) La voluntad procreacional}

La voluntad en la filiación juega un papel trascendental, aun cuando el derecho de familia se caracteriza por un conjunto de normas imperativas que, en esta materia, se pueden apreciar sensiblemente disminuidas, ya que cada vez hay una mayor intervención de la autonomía de los sujetos en cuya relación intervienen (Guzmán Ávalos, Valdés Martínez, 2017). Desde el campo jurídico, se observa que el elemento relevante para la determinación de la filiación en el campo de las TRHA es la voluntad procreacional, argumento central, cuestión crucial e imposible de soslayar.

Así, cabe señalar lo receptado en el art. 562 del CCyC, eje central o columna vertebral de la determinación de la filiación derivada de las TRHA: la voluntad procreacional, dejando expresamente consignado que es el elemento primordial para determinar el vínculo filial en los casos de TRHA, se haya utilizado el material genético de los miembros de la pareja, de uno de ellos, o de un tercero, residiendo aquí una de las diferencias sustanciales con la filiación por naturaleza.

Ahora bien, para entender la aplicación de este principio a la GS, se puede decir que ésta es "la intención de querer engendrar un hijo con material genético propio, acudiendo a la implantación del embrión en el vientre de una tercera persona para su gestación y alumbramiento posterior. Sucede que esta tercera persona carece de voluntad; falta el elemento central que atribuye o determina la filiación en las técnicas de reproducción humana asistida: la voluntad procreacional” (Kemlemajer, Lamm, Herrera, 2013). Es decir, serán los progenitores del niño o niña que nazca quienes hayan expresado su voluntad plasmada en el correspondiente consentimiento previo, informado y libre antes de la realización de algún tratamiento de TRHA -entre ellos, la GS-, generando a partir de allí, todos los derechos y 
Notrica, F.P. Hay que decir que sí a una regulación de gestación por sustitución. Derecho y Ciencias Sociales. Abril 2018. $\mathrm{N}^{\circ}$ 18. (Las familias y el derecho de las familias a dos años de vigencia del Código Civil y Comercial) Pgs 82-98. ISNN 1852-2971. Instituto de Cultura Jurídica y Maestría en Sociología Jurídica. FCJ y S. UNLP

deberes que nacen con el vínculo filial (Notrica, Curti, Cotado, 2017). Esto implica una máxima y particular situación en el campo de la GS: dejar de lado la aplicación del principio clásico "mater semper certa est".

Esta noción implicó una ruptura heterobiologicista sobre el cual estaba armado el instituto jurídico de la filiación, razón por lo cual, "desde una perspectiva psicoconstitucional-convencional, la voluntad procreacional puede ser definida como el deseo de tener un hijo o hija sostenido por el amor filial que emerge de la constitución subjetiva de las personas" (Gil Domínguez, 2014:13)

Por otro lado, vale recordar que la identidad se determina por tres elementos: genético, biológico y voluntario. El que determina la identidad del niño por nacer y su vínculo jurídico, es el elemento volitivo, reflejado en la voluntad procreacional, exteriorizado a través de las formalidades prescriptas en los arts. 560 y $561 \mathrm{del} \mathrm{CCyC.}$

\section{b) El interés superior del niño}

Es sabido que el interés superior del niño, tal como lo estableció el Comité de los Derechos del Niño de la ONU en la Observación General No 5 (2003), es un principio rector que todos los órganos o instituciones legislativos, administrativos y judiciales han de aplicar en todas las medidas que adopten, incluyendo las que no se refieren directamente a los niños, pero los afectan (párrafo 13). De manera más actual, este mismo organismo en la Observación General N 14 (2013) focalizado en este principio, agrega que el interés suprior del niño, tiene un concepto triple: 1) es un derecho sustantivo al entender que el derecho del niño a que su interés superior sea una consideración primordial que se evalúe y tenga en cuenta al sopesar distintos intereses para tomar una decisión sobre una cuestión debatida, y la garantía de que ese derecho se pondrá en práctica siempre que se tenga que adoptar una decisión que afecte a un niño, a un grupo de niños concreto o genérico o a los niños en general; 2) un principio jurídico interpretativo fundamental ya que si una disposición jurídica admite más de una interpretación, se elegirá la interpretación que satisfaga de manera más efectiva el interés superior del niño; y 3) una norma de procedimiento porque siempre que se tenga que tomar una decisión que afecte a un niño el proceso de adopción de decisiones deberá incluir una

\footnotetext{
${ }^{1}$ Vale tener en cuenta que el principio "mater semper certa est", según el cual madre es siempre cierta, porque es ella la mujer que da a luz, se encuentra en crisis, ya que los procedimientos de GS lo dejan de lado, por cuanto no se considera "madre" a quien da a luz, sino que, justamente, quien gesta y quien es considerada madre, está disociado en dos personas distintas.
} 
Notrica, F.P. Hay que decir que sí a una regulación de gestación por sustitución. Derecho y Ciencias Sociales. Abril 2018. $\mathrm{N}^{\circ}$ 18. (Las familias y el derecho de las familias a dos años de vigencia del Código Civil y Comercial) Pgs 82-98. ISNN 1852-2971. Instituto de Cultura Jurídica y Maestría en Sociología Jurídica. FCJ y S. UNLP

estimación de las posibles repercusiones (positivas o negativas) de la decisión en el niño o los niños interesados.

La Corte Interamericana de Derechos Humanos en la Opinión Consultiva 17/2002 sobre Condición Jurídica y Derechos Humanos del Niño, expresó que el interés superior del niño ha de ser entendido "como la premisa bajo la cual se debe interpretar, integrar y aplicar la normativa de la niñez y la adolescencia (...) se funda en la dignidad misma del ser humano, en las características propias de los niños, y en la necesidad de propiciar el desarrollo de éstos, con pleno aprovechamiento de sus potencialidades, así como en la naturaleza y alcances de la Convención sobre los Derechos del Niño (...) y es el punto de referencia para asegurar la efectiva realización de todos los derechos contemplados en este instrumento, cuya observación permitirá al sujeto el más amplio desenvolvimiento de sus potencialidades".

De igual forma y desde una mirada realista, sincera y cierta, la doctrina ha sostenido que "si bien el concepto jurídico del interés superior del niño es indeterminado, no es menos cierto que "el niño no estaría en este mundo de no haberse recurrido a la gestación por sustitución por parte de una o dos personas que desearon fervientemente su existencia; tanto lo quisieron, que no pudiendo hacerlo por otro método recurrieron a uno que implica dificultades de todo tipo (legales, económicas, fácticas, etc.)"(Kemelmajer, Herrera, Lamm, 2012).

Paradójicamente, se ha utilizado este principio rector, tanto para reafirmarse la postura a favor, como la que está en contra de la GS. Sambrizzi (2015) y Basset (2015) contrarios a la gestación por sustitución utilizan "el interés superior del niño" basando su postura en la posibilidad de facilitar el tráfico de niños/as mediante su compraventa o a través de adopciones ilegales y en el riesgo de caer en la cosificación de los/las niños/as y de la reproducción y los problemas relacionados con el conocimiento de los orígenes biológicos. Esta dicotomía entre quienes están a favor y quienes en contra tiene que ver con la tarea de darle contenido a este concepto jurídico indeterminado. Frente a esta práctica cabría preguntarse: ¿cuál es el "interés superior del niño"?. Es cierto que se trata de un concepto abierto, pero algo es seguro: esa apertura no puede ser utilizada para esconder prejuicios, ideologías, ni mucho menos para privar de derechos a los niños (Kemelmajer, Lamm, 2014). Es más, se podría partirse desde un punto central: este niño o niña no habría nacido de no haberse recurrido a la GS por parte de una o dos personas que desearon que naciera. Tan grande fue el deseo, que no pudiendo hacerlo por otro método, recurrieron a uno que implica dificultades de todo tipo (legales, afectivas, económicas, fácticas, etc.). 
Notrica, F.P. Hay que decir que sí a una regulación de gestación por sustitución. Derecho y Ciencias Sociales. Abril 2018. $\mathrm{N}^{\circ}$ 18. (Las familias y el derecho de las familias a dos años de vigencia del Código Civil y Comercial) Pgs 82-98. ISNN 1852-2971. Instituto de Cultura Jurídica y Maestría en Sociología Jurídica. FCJ y S. UNLP

Pretendiéndose contestar dicha pregunta, cabe, en primer término, que el interés superior del niño en la GS debe estar siempre bien presente desde una obligada perspectiva transversal de su práctica. Bajo esta premisa, la doctrina utilizó este principio expresándose de la siguiente manera: "Regular la gestación por sustitución es la solución que mejor satisface el interés superior del niño, porque desde el mismo momento del nacimiento el niño encuentra una familia que lo quiere; además, él mismo no hubiese existido de no haber mediado el acuerdo. El interés superior del niño se asegura limitando el poder de las partes, y esto sólo puede hacerse a través de la regulación legal de estos convenios. Ese interés exige contar con un marco legal que proteja al niño, le brinde seguridad jurídica y le garantice una filiación acorde a la realidad volitiva" (Lamm, 2012:15).

Desde una mirada más integral, hasta la fecha, ningún estudio científico de psicología prenatal relativo a la gestación por sustitución ha demostrado que este modo de gestar suponga un daño para el niño, ni siquiera potencial. En este sentido, la Lic. Barón afirma: "La estabilidad emocional que un niño necesita para su bienestar está más relacionada con la historia previa, la personalidad de sus padres y el afecto que les brindan que con la forma en la que fueron concebidos" 2 .

\section{c) Derecho a fundar una familia}

Los autores que defienden este argumento parten, en especial, del derecho a procrear y a formar una familia, como un derecho humano inherente a toda persona y en función del reconocimiento que realiza la legislación universal y regional. Así lo contempla la Declaración Americana de los Derechos y Deberes del Hombre que, en su art. VI establece que "toda persona tiene el derecho a construir una familia, elemento fundamental de la sociedad y a recibir protección para ella”. También lo recepta el Pacto Internacional de Derechos Civiles y Políticos al disponer en su art. 23 (punto 2) que "Se reconoce el derecho del hombre y de la mujer a contraer matrimonio y a fundar una familia si tienen edad para ello"; y la Convención Americana sobre Derechos Humanos en su art. 17 -segundo párrafoque reconoce también "el derecho del hombre y la mujer a contraer matrimonio y a fundar una familia si tienen la edad y las condiciones requeridas para ello por las leyes internas, en la medida en que éstas no afecten al principio de no discriminación establecido en esta Convención".

\footnotetext{
2 Entrevista sobre "Nuevas Formas de Maternidad" en Diario Perfil (Argentina), 08/04/2012, en http://www.maternidadsubrogada.com.ar/index.php/publicaciones/46-nacer-de-un-utero-alquilado-no-afecta-lavida-de-los-chicos, consultada el día 5/03/2018.
} 
Notrica, F.P. Hay que decir que sí a una regulación de gestación por sustitución. Derecho y Ciencias Sociales. Abril 2018. $\mathrm{N}^{\circ}$ 18. (Las familias y el derecho de las familias a dos años de vigencia del Código Civil y Comercial) Pgs 82-98. ISNN 1852-2971. Instituto de Cultura Jurídica y Maestría en Sociología Jurídica. FCJ y S. UNLP

El Comité de Derechos Humanos en la Observación General No 19 sostuvo: "5. El derecho a fundar una familia implica, en principio, la posibilidad de procrear y de vivir juntos. Cuando los Estados Partes adopten políticas de planificación de la familia, éstas han de ser compatibles con las disposiciones del Pacto y sobre todo no deben ser ni discriminatorias ni obligatorias. Asimismo, la posibilidad de vivir juntos implica la adopción de medidas apropiadas, tanto en el plano interno cuanto, según sea el caso, en cooperación con otros Estados, para asegurar la unidad o la reunificación de las familias, sobre todo cuando la separación de sus miembros depende de razones de tipo político, económico o similares".

Siguiendo esta misma línea, la Corte Interamericana de Derechos Humanos, en el fallo reiterado precedente "Artavia Murillo contra Costa Rica”, efectúa una interpretación amplia del artículo 7 de la Convención Americana al señalar que

éste incluye un concepto de libertad en un sentido extenso como la capacidad de hacer y no hacer todo lo que esté lícitamente permitido. En otras palabras, constituye el derecho de toda persona de organizar, con arreglo a la ley, su vida individual y social conforme a sus propias opciones y convicciones. La Corte ha resaltado el concepto de libertad y la posibilidad de todo ser humano de auto-determinarse y escoger libremente las opciones y circunstancias que le dan sentido a su existencia, conforme a sus propias opciones y convicciones. La vida privada incluye la forma en que el individuo se ve a sí mismo y cómo decide proyectarse hacia los demás, y es una condición indispensable para el libre desarrollo de la personalidad. (Párrafo 142 y ss.)

Además, se agrega que "fundar una familia procreando o no depende, a fin de cuentas, del plan de vida de cada individuo. Esta planificación va asociada a la libertad reproductiva que incluye como elementos constitutivos la elección de procrear, con quién y por qué medios, la elección del contexto social en que la reproducción tiene lugar, la elección de cuándo reproducirse, y la elección de cuántos hijos tener” (Famá, 2009: 279).

En el ámbito nacional constitucional, se brinda la denominada "protección integral" a la familia (art. 14 bis CN). Por su parte, el art. 16 la ampara fundado en el principio de igualdad entre todos los habitantes y como se ha dicho “...el art. 19 establece y protege una amplia zona de autonomía y desarrollo personal, permitiendo que cada persona pueda formar el tipo de familia que desee siempre que no conculque derechos de terceros." (Herrera y Lamm, 2015: 310).

Este derecho de fundar una familia -por cierto, pieza fundamental en los planes de vida de todo ser humano-, se va a determinar en base a la libertad de cada persona, pudiendo 
Notrica, F.P. Hay que decir que sí a una regulación de gestación por sustitución. Derecho y Ciencias Sociales. Abril 2018. $\mathrm{N}^{\circ}$ 18. (Las familias y el derecho de las familias a dos años de vigencia del Código Civil y Comercial) Pgs 82-98. ISNN 1852-2971. Instituto de Cultura Jurídica y Maestría en Sociología Jurídica. FCJ y S. UNLP

formar su familia integrada solo por los miembros de la pareja o también teniendo hijos, eligiendo cada uno la cantidad que desea. En este último caso, se constituye uno de los pilares que justifica la posibilidad de hacerlo por medio de la procreación. Y esto se observa, de manera elocuente, en los casos conformado por parejas de hombres o por un hombre solo en el que la GS es la única opción o forma de acceder a este derecho con material de los propios requirentes o quienes tienen la voluntad de ser padres.

\section{d) El derecho a la identidad}

Para poder comprender la complejidad con la que se recepta el derecho a la identidad en la filiación derivada por el uso de las TRHA y la particularidad que ostenta en los niños nacidos mediante estos tratamientos, es menester explicar detalladamente las aristas que posee el derecho a la información y a conocer su realidad genética y gestacional, tal como lo regula en forma expresa el actual Código Civil y Comercial, en los arts. 563 y 564.

La identidad constituye un concepto complejo que posee múltiples aristas e involucra distintos derechos para los diferentes campos del conocimiento. Así, Fromm la define como una necesidad afectiva ("sentimiento"), cognitiva ("conciencia de sí mismo y del otro como personas diferentes") y activa (el ser humano tiene que "tomar decisiones" haciendo uso de su libertad y voluntad) (Fromm, 1967).

Desde el punto de vista jurídico, los alcances y contenidos del derecho a la identidad son referidos por un reconocido jurista (Fernández Sessarego, 1996) quien expresa que la identidad de la persona no se agota con la información referida a los aspectos que hacen a la faz estática, sino que ella debe incluir el conjunto de atributos y cualidades que definen la personalidad de cada sujeto. Según dicho autor, la identidad de una persona está compuesta por distintos elementos, y se subdivide en dos fases. Por una parte, están aquéllos que permanecen estables a lo largo de la vida del sujeto - $\mathrm{O}$, al menos, es muy poco probable que varíen-. Estos elementos, que incluyen la composición genética, el sexo, y el nombre, conforman lo que se conoce como "identidad estática". Por otro lado, están los elementos que cambian constantemente en una persona, como por ejemplo sus opiniones, sus preferencias. Son elementos psicológicos, que están ligados a la educación y al entorno cultural del sujeto, y conforman su "identidad dinámica".

En igual sentido, se sostiene (Cabrera, Codeglia, 1995) que el derecho a la identidad no se limita a considerar el aspecto físico o biológico de la persona. Comprende también el bagaje espiritual, intelectual, político, profesional, etc., a través del cual el individuo se 
Notrica, F.P. Hay que decir que sí a una regulación de gestación por sustitución. Derecho y Ciencias Sociales. Abril 2018. $\mathrm{N}^{\circ}$ 18. (Las familias y el derecho de las familias a dos años de vigencia del Código Civil y Comercial) Pgs 82-98. ISNN 1852-2971. Instituto de Cultura Jurídica y Maestría en Sociología Jurídica. FCJ y S. UNLP

proyecta socialmente al exteriorizar de alguna manera estos aspectos propios de su personalidad.

El CCyC se ocupa expresamente del derecho a la información de las personas nacidas por TRHA, reconociendo la especificidad que detenta el derecho a la identidad en las TRHA heterólogas en los arts. 563 y 564, disponiendo de esta manera que la información relativa a la persona que ha nacido por el uso de técnicas de reproducción humana asistida con gametos de un tercero debe constar en el correspondiente legajo base para la inscripción del nacimiento y que a petición de aquéllas, se podrá: a) obtener del centro de salud interviniente información relativa a datos médicos del donante, cuando es relevante para la salud; b) revelar la identidad del donante, por razones debidamente fundadas, evaluadas por la autoridad judicial por el procedimiento más breve que prevea la ley local.

Dicho todo esto, entonces, se debe dejar en claro que a los niños nacidos por GS se debería extender este derecho a la información en lo relativo a conocer su realidad gestacional, es decir, saber quién fue la persona que lo gestó y todo lo que rodea a ese proceso ya que se trata más de un proceso que de un momento.

\section{e) EI derecho a gozar de los beneficios y avances de la ciencia y la tecnología}

Los progresos de la ciencia y la tecnología han impactado en la medicina reproductiva y, consecuentemente, en las relaciones familiares (Dickens, 2014).

En primer lugar, cabe destacar que según la idiosincrasia regional actual "El modelo latinoamericano enfatiza un «bios» humano y un «ethos» comunitario. Esta es la razón por la cual la bioética es hoy más un movimiento político o de reforma social que una disciplina académica restringida al dominio de la atención de la salud. En la bioética latinoamericana los principios de solidaridad y justicia juegan el papel central (...) las políticas de salud latinoamericana abrazan el acceso universal al cuidado de la salud y ponen el acento en la justicia distributiva y la equidad en la asignación de recursos para la salud" (Mainetti, 2016).

Además, decirse que las TRHA tienen una particularidad que las diferencia de otras prestaciones de salud en sentido amplio y ello gira en torno a los altos costos, en especial, las técnicas de alta complejidad como así los procedimientos de gestación por sustitución, ya que, al comprometer a una tercera persona, los costos médicos involucrados son mayores.

En el ámbito convencional, sin duda, se respaldan e impulsan las ideas de beneficiarse de la ciencia, sin que ello se encuentre supeditado a un impedimento de salud. Así, la Asamblea General de las Naciones Unidas en su Declaración sobre la utilización del progreso 
Notrica, F.P. Hay que decir que sí a una regulación de gestación por sustitución. Derecho y Ciencias Sociales. Abril 2018. $\mathrm{N}^{\circ}$ 18. (Las familias y el derecho de las familias a dos años de vigencia del Código Civil y Comercial) Pgs 82-98. ISNN 1852-2971. Instituto de Cultura Jurídica y Maestría en Sociología Jurídica. FCJ y S. UNLP

científico y tecnológico en el interés de la paz y el beneficio de la humanidad ${ }^{3}$ ha establecido: "Los Estados deben adoptar las medidas necesarias para que la utilización de los logros de la ciencia y la tecnología contribuya a la realización más plena posible de los derechos humanos y las libertades fundamentales sin discriminación alguna por motivos de raza, sexo, idioma o creencias religiosas"; ello en total consonancia con lo previsto en el art. 15 b) del Pacto Internacional de Derechos Económicos, Sociales y Culturales al disponer que "los Estados Partes en el presente Pacto reconocen el derecho de toda persona a: [...] b) gozar de los beneficios del progreso científico y de sus aplicaciones". En este mismo sentido se expide la Declaración Americana al establecer en el art. XIII que "Toda persona tiene el derecho de [...] disfrutar de los beneficios que resulten de los progresos intelectuales y especialmente de los descubrimientos científicos".

A su vez, el derecho humano a gozar del beneficio o progreso científico es receptado de manera expresa por la Corte IDH en el ya mencionado caso "Artavia Murillo", al sentenciar que

Finalmente, el derecho a la vida privada y la libertad reproductiva guarda relación con el derecho de acceder a la tecnología médica necesaria para ejercer ese derecho. El derecho al goce de los beneficios del progreso científico ha sido reconocido internacionalmente y, en el ámbito interamericano, se encuentra contemplado en el artículo XIII de la Declaración Americana y en el artículo 14.1 b) del Protocolo de San Salvador. Cabe mencionar que la Asamblea General de Naciones Unidas, en su Declaración sobre este derecho, señaló la relación entre éste y la satisfacción de las necesidades materiales y espirituales de todos los sectores de la población. Por tanto, y conforme al artículo 29 b) de la Convención Americana, el alcance de los derechos a la vida privada, autonomía reproductiva y a fundar una familia, derivado de los artículos 11.2 y 17.2 de la Convención Americana, se extiende al derecho de toda persona a beneficiarse del progreso científico y de sus aplicaciones. Del derecho de acceso al más alto y efectivo progreso científico para el ejercicio de la autonomía reproductiva y la posibilidad de formar una familia se deriva el derecho a acceder a los mejores servicios de salud en técnicas de asistencia reproductiva, y, en consecuencia, la prohibición de restricciones desproporcionadas e innecesarias de iure o de facto para ejercer las decisiones reproductivas que correspondan en cada persona" (Parágrafo 150)

\footnotetext{
3 Proclamada por la Asamblea General en su Resolución No 3384, de 10/11/1975. Disponible en: http://www.ohchr.org/SP/ProfessionalInterest/Pages/ScientificAndTechnologicalProgress.aspx, compulsado el $17 / 09 / 2016$
} 
Notrica, F.P. Hay que decir que sí a una regulación de gestación por sustitución. Derecho y Ciencias Sociales. Abril 2018. $\mathrm{N}^{\circ}$ 18. (Las familias y el derecho de las familias a dos años de vigencia del Código Civil y Comercial) Pgs 82-98. ISNN 1852-2971. Instituto de Cultura Jurídica y Maestría en Sociología Jurídica. FCJ y S. UNLP

y reafirmándolo en una nueva resolución adoptada en el proceso de seguimiento para el cumplimiento de la sentencia, de fecha 26/02/2016.

En este sentido, la GS debe ser regulada, porque es insostenible el silencio legislativo frente a tantos derechos humanos y principios constitucionales-convencionales que así la respaldan.

\section{f) El derecho a la salud y a la salud sexual y reproductiva}

El derecho a la salud como derecho humano está reconocido constitucionalmente en los arts. 14 y 33 de la Constitución Nacional, y por distintos tratados internacionales de derechos humanos con jerarquía constitucional (art. 75, inc. 22). En este sentido, aparece la Declaración Universal de Derechos Humanos, en donde se afirma que "toda persona tiene derecho a un nivel de vida adecuado que le asegure, así como a su familia, la salud y en especial la alimentación, el vestido, la vivienda, la asistencia médica y los servicios sociales necesarios" (art. 25, párrafo 1); el Pacto Internacional de Derechos Económicos, Sociales y Culturales que establece que los Estados parte reconocen "el derecho a toda persona al disfrute del más alto nivel posible de salud física y mental" (art. 12, párrafo 1) e indica distintas "medidas que deberán adoptar los Estados parte... a fin de asegurar la plena efectividad de este derecho" (art. 12, párrafo 2); la Convención Internacional sobre la Eliminación de todas las Formas de Discriminación Racial así como la Convención sobre la Eliminación de todas las Formas de Discriminación contra la Mujer mencionan en sus textos al derecho a la salud.

Cabe señalar además que, la Organización Mundial de la Salud define a la salud como un "estado de completo bienestar físico, mental y social", permitiendo determinar que se trata de un derecho fundamental destinado a preservar la dignidad y calidad de vida de las personas (Krasnow, 2010).

Retomando el ya mencionado fallo "Artavia Murillo", se explicó que "Por su parte, la CDPD establece que las personas con discapacidad "incluyen a aquellas que tengan deficiencias físicas, mentales, intelectuales o sensoriales a largo plazo que, al interactuar con diversas barreras, puedan impedir su participación plena y efectiva en la sociedad, en igualdad de condiciones con las demás". La discapacidad resulta de la interacción entre las limitaciones funcionales de una persona y las barreras existentes en el entorno que impiden el ejercicio pleno de sus derechos y libertades". (Art. 1 CDPD).

Dentro del derecho a la salud aparece el derecho a la salud sexual y reproductiva entendiéndose como "la capacidad de disfrutar de una vida sexual satisfactoria y sin riesgos y 
Notrica, F.P. Hay que decir que sí a una regulación de gestación por sustitución. Derecho y Ciencias Sociales. Abril 2018. $\mathrm{N}^{\circ}$ 18. (Las familias y el derecho de las familias a dos años de vigencia del Código Civil y Comercial) Pgs 82-98. ISNN 1852-2971. Instituto de Cultura Jurídica y Maestría en Sociología Jurídica. FCJ y S. UNLP

de procrear, y la libertad para decidir hacerlo o no hacerlo, cuándo y con qué frecuencia", idea desarrollada en el marco de la Observación General No 22 dedicada al "Derecho a la Salud Sexual y Reproductiva, artículo 12 del Pacto Internacional de Derechos Económicos, Sociales y Culturales"4 emitida por el Comité de Derechos Económicos Sociales y Culturales, comprendiéndose por tres acciones diferentes y complementarias: información, prevención y planificación.

En este orden de ideas, se señala "...que hay un derecho inalienable a la reproducción que tiene soporte en el derecho constitucional a constituir una familia..." y que este derecho reproductivo "... aparece con toda claridad en el artículo 16, inciso 21 , apartado e, de la Convención sobre Eliminación de todas las formas de Discriminación contra la Mujer..." (Minkyersky, 2009).

En definitiva, hay que decir que se basa en una noción robusta de la autonomía de las personas, en tanto manifestación concreta de la libertad individual, inspirada tanto en el ordenamiento jurídico interno como en la Constitución Nacional, llamada autonomía personal, libertad procreacional o reproductiva, intimidad o privacidad (frente a injerencias estatales) de los requirentes y la gestante, etc. (Brodsky, 2015).

\section{g) El principio de igualdad y no discriminación}

Otro de los principios que se utilizan para expresarse favorablemente a esta técnica es el de igualdad y no discriminación, relacionándose con el derecho a fundar una familia, en condiciones de igualdad y libertad, sin condicionamientos de ningún tipo, especialmente, en cuanto a la orientación sexual de los miembros de la pareja o de una persona sola.

En este sentido, se expresó que “(...) desde la consagración constitucionalconvencional del derecho humano a fundar una familia con su inmediata derivación en los derechos reproductivos, es que la igualdad debe ser real, reconocida por la ley, y sin discriminación hacia un sector de la población que debido a problemas de salud -infertilidado a su orientación sexual, queda al margen de la posibilidad de procrear." (Notrica, Melón, González, 2016, 9).

Es que la GS representa la única opción que tiene una pareja compuesta por dos hombres o un hombre solo, de tener un hijo genéticamente propio (aunque sólo de uno de ellos), por lo que, conforme a los principios de libertad, igualdad y no discriminación, la

\footnotetext{
${ }^{4}$ Comité de Derechos Económicos, Sociales y Culturales, Observación General $\mathrm{N}^{\circ} 22$, "Theright to sexual and reproductive health -article 12 of the International Covenanton Economic, Social and Cultural Rights-", disponible en: http://www.colectivoderechofamilia.com/wp-content/uploads/2015/04/Observaci\%C3\%B3n-N22-DESC_Derechos-sexuales-y-Reproductivos-02-05-2016.pdf, consultada el 16/09/2016.
} 
Notrica, F.P. Hay que decir que sí a una regulación de gestación por sustitución. Derecho y Ciencias Sociales. Abril 2018. $\mathrm{N}^{\circ}$ 18. (Las familias y el derecho de las familias a dos años de vigencia del Código Civil y Comercial) Pgs 82-98. ISNN 1852-2971. Instituto de Cultura Jurídica y Maestría en Sociología Jurídica. FCJ y S. UNLP

figura, debe regularizarse en beneficio de todos los involucrados, especialmente teniendo en miras a los niños nacidos, para que su realidad filiatoria se vea reflejada en sus partidas de nacimiento.

Siguiendo este orden de ideas, justamente, en el fallo de la Corte IDH “Atala Riffo c/ Chile", del 24/02/2012, se ha dicho que

El Tribunal constata que, en el marco de las sociedades contemporáneas se dan cambios sociales, culturales e institucionales encaminados a desarrollos más incluyentes de todas las opciones de vida de sus ciudadanos, lo cual se evidencia en la aceptación social de parejas interraciales, las madres o padres solteros o las parejas divorciadas, las cuales en otros momentos no habían sido aceptadas por la sociedad. En este sentido, el Derecho y los Estados deben ayudar al avance social, de lo contrario se corre el grave riesgo de legitimar y consolidar distintas formas de discriminación violatorias de los derechos humanos. (Párrafo 120).

En el mismo sentido, la Corte IDH, en el caso "Duque contra Colombia" del 26/2/2016 ${ }^{5}$ que versó sobre la vulneración de la protección de familias diversas a través de la discriminación por la orientación sexual, se entendió que la normativa colombiana que "no permitía el pago de pensiones a parejas del mismo sexo, era una diferencia de trato que vulneraba el derecho a la igualdad y no discriminación, por lo que constituyó efectivamente un hecho ilícito internacional" (párrafo 125).

Es que, "la combinación dentro de nuestro sistema de fuentes de los casos "Artavia Murillo vs. Costa Rica" y "Fornerón vs. Argentina" con la ley 26.682 más el decreto reglamentario 956/2013 remite directamente a la existencia de un derecho a la gestación por sustitución en pos de evitar cualquier forma de discriminación y sin que se tenga que acreditar una situación de infertilidad patológica." (Gil Domínguez, 2015, 237).

Cabe concluir que el principio de igualdad y no discriminación fue el puntapié inicial para repensar el modelo de familia clásico y tradicional, produciendo una ruptura en el derecho de las familias, justamente, teniendo una mirada inclusiva, democrática y plural, relacionado, caro está, con el derecho de toda persona a vivir en familia, de la manera que mejor se piense, con libertad y autodeterminación.

\section{h) La fuerza de la realidad}

\footnotetext{
5 CIDH, 26/02/2016, “Caso Duque v. Colombia”, disponible en: http://www.corteidh.or.cr/docs/casos/articulos/seriec_310_esp.pdf, compulsado el 15/01/2017.
} 
Notrica, F.P. Hay que decir que sí a una regulación de gestación por sustitución. Derecho y Ciencias Sociales. Abril 2018. $\mathrm{N}^{\circ}$ 18. (Las familias y el derecho de las familias a dos años de vigencia del Código Civil y Comercial) Pgs 82-98. ISNN 1852-2971. Instituto de Cultura Jurídica y Maestría en Sociología Jurídica. FCJ y S. UNLP

Al no existir norma específica en el ordenamiento jurídico argentino que regule la figura, todo queda librado a la discrecionalidad judicial que deriva de dicha falta de regulación. Más allá de eso, cabe poner de resalto que la jurisprudencia a lo largo y ancho del país ha consolidado la aceptación de la gestación por sustitución: existen ya veintitrés fallos que han sido resueltos favorablemente y uno, en el que, si bien se rechazó la demanda, ha reconocido a la GS como una práctica permitida. Finalmente, se encuentra pendiente de tratamiento un caso por la Corte Suprema de Justicia de la Nación; esto sin contabilizar los fallos de GS internacional ${ }^{6}$.

\section{3.- Conclusiones}

La GS tiene un fin primordial en la vida de las personas: tener un hijo o hija y formar la familia que tanto se desea.

\footnotetext{
${ }^{6} \mathrm{Al}$ respecto, ver los siguientes fallos: Cámara de Apelaciones en lo Civil, Comercial y Laboral Gualeguaychú, “B., M. A. c. F. C., C. R.”, 14/04/2010, cita La Ley online: AR/JUR/75333/2010. Juzgado de Familia de Gualeguay, "B. M. A. c/ F. C. C. R. | ordinario", 19/11/2013. Cita Microjuris online MJ-JU-M-83567-AR | MJJ83567 - Juzgado nacional en lo Civil No 86, "N.N. o DGMB s/ inscripción de nacimiento"”, 18/06/2013, cita Microjuris: MJ-DOC-6401-AR | MJD6401 - Tribunal de Familia № 7 de Rosario, "F.M. L y otra s/autorización judicial", 2/12/2014, Cita online AR/JUR/90178/2014. - Juzgado Nacional en lo Civil No 102, 18/05/2015, "C., F. A. y otro c/ R. S., M. L. s/impugnación de maternidad”, en ABELEDO PERROT No: AR/JUR/12711/2015. Juz. Nac. Civ. $\mathrm{N}^{\circ} \quad 83$, "NN O, s/inscripción de nacimiento", 30/06/2015, en http://colectivoderechofamilia.com/categoria/jurisprudencia/jurisprudencia-nacional/, compulsado el 7/2/2017 Juzgado de Familia $N^{\circ} 1$ de Mendoza, "A. V. O., A. C. G. Y J. J. F", 29/7/2015, cit. - Juzgado de Familia N $^{\circ} 1$ de Mendoza, "C.M. E. Y J. R. M. POR INSCRIP. NACIMIENTO.”, 15/12/2015, en http://colectivoderechofamilia.com/fa-pcial-juz-flia-no1-mendoza-gestacion-por-sustitucion/ Compulsada el 7/02/2017 - Juzgado de Familia Nº 9 de San Carlos De Bariloche. 29 -12- 2015. "Dato Reservado. Expte. Nro. 10178 14." Infojus: NV13851. http://www.infojus.gob.ar/maternidad-subrogada-autorizan-transferenciaembrion-vientre-subrogado-nv13851-2015-12-29/123456789-0abc-158-31ti-lpssedadevon. Compulsada el 22/03/2016. - Juzgado Familia nro. 7, Lomas de Zamora, "H. M. Y OTRO/A S/MEDIDAS PRECAUTORIAS (art.232 del CPCC)", 30/12/2015, en Microjuris online, MJ-JU-M-97208-AR- Tribunal Colegiado de Familia N $^{\circ}$ 5 de Rosario, "S G G. y OTROS S/ FILIACION", 27/05/2016, http://maestrosdelderecho.com.ar/jurisprudenciagestacion-por-sustitucion/, compulsado el 8/02/2017. - Juzgado Nacional Civil N 7, “A. R., C y otros c/ C., M. J. s/impugnación de filiación", 23/05/2016, Inédito. - Juzgado Unipersonal de Familia $\mathrm{N}^{\circ} 2$ de Moreno, "S. P., B. B. c/S. P., R. F. s/materia a categorizar", 4/07/2016, inédito. - Juzgado Nacional en lo Civil No 8, "B., B. M. y otro c/ G., Y. A. s/impugnación de filiación", 20/09/2016, http://www.colectivoderechofamilia.com/fa-nac-juznac-civ-no-8-trha-gestacion-por-sustitucion/, compulsado el día 8/02/2017. - Juzgado de Familia N³ de Gral. San Martín, 22/08/2016, "M., I. M. y otro s/autorización judicial, inédito. - Juzgado de Familia No 12 de Lomas de Zamora, "G. M., C y otro c/ W. B., A. V s/rectificación de partida”, 3/10/2016, inédito. - Juzgado Familia $\mathrm{N}^{\circ}$ 7, Lomas de Zamora, "B. J. D. y otros s/materia a categorizar", 30/11/2016, Inédito. - Juzgado Nacional en lo Civil N 81, “S., I. N. y otro c/A., C. L. s/Impugnación de Filiación”, 14/06/2017, Inédito. - Juzgado de Familia N 5 de Viedma, "RESERVADO S/ AUTORIZACION JUDICIAL (f)", 7/07/2017, Inédito - Juzgado de Familia $\mathrm{N}^{\circ} 1$ de Mendoza, "M.M.C y M.G.J. y R.F.N. por medidas autosatisfactivas", 6/09/2017, inédito. - Juzgado Nacional en lo Civil $\mathrm{N}^{\circ}$ 4, "S. T., V. s/inscripción de nacimiento", 20/10/2017, inédito. - Juzgado de Familia $\mathrm{N}^{\circ}$ 2 de Córdoba, "R., L. S. Y OTROS - SOLICITA HOMOLOGACION", 22/11/2017, Inédito. - Tribunal Colegiado No 7 de Rosario, "H., M.E. Y OTROS S/ VENIAS Y DISPENSAS”, 5/12/2017, Inédito. - Juzgado de Familia $\mathrm{N}^{\circ} 1$ de Mendoza, "S. M. S.; T. C. J.; B. P. V. por medidas autosatisfactivas", 15/02/2018, Inédito. Juzgado de Familia $N^{\circ} 6$ de San Isidro, "S., M. J. y otro s/autorización judicial”, Inédito. -
} 
Notrica, F.P. Hay que decir que sí a una regulación de gestación por sustitución. Derecho y Ciencias Sociales. Abril 2018. $\mathrm{N}^{\circ}$ 18. (Las familias y el derecho de las familias a dos años de vigencia del Código Civil y Comercial) Pgs 82-98. ISNN 1852-2971. Instituto de Cultura Jurídica y Maestría en Sociología Jurídica. FCJ y S. UNLP

Para ello, hay que darles opciones a todas las personas, en igualdad de condiciones, con diferentes posibilidades, que seguramente sean distintas las unas de las otras. Para ello, se requiere de un marco jurídico que garantice el ejercicio de los derechos, que respete y promueva el derecho de las personas a construir paternidades y maternidades libres y responsables, reconociendo la pluralidad y diversidad que existe en nuestra sociedad y se deje de invisibilizar a una realidad que está pidiendo a gritos que le den nombre y cuerpo, para asegurar el derecho humano de toda persona a fundar y vivir en familia, la autodeterminación de cada una de ellas en su individualidad, gozando del avance de las nuevas tecnologías, respetando el derecho a la identidad del niño o niña que nacerá y efectivizando los derechos de cada uno de los intervinientes. Para ello, la doctrina internacional de los Derechos Humanos nos llena de respuestas y soluciones para lograr este cometido.

\section{4- Fallos de la Corte Interamericana de Derechos Humanos}

"Artavia Murillo y otros c. Costa Rica", de fecha 28/11/2012Disponible en: http://www.corteidh.or.cr/docs/casos/articulos/seriec_257_esp.pdf, compulsado 17/09/2016, consultado el 17/04/2018.

"Atala Rifo y niñas v. Chile", de fecha 24 de febrero de 2012. Disponible http://corteidh.or.cr/docs/casos/articulos/seriec_239_esp.pdf, compulsado el 15/01/2017.

“ Duque v. Colombia", de fecha 26/02/2016, disponible en: http://www.corteidh.or.cr/docs/casos/articulos/seriec_310_esp.pdf, compulsado el 15/01/2017.

\section{Bibliografía}

Basset U. (2015). El consentimiento informado y la filiación por procreación asistida en el Código Civil y Comercial. En Revista Jurídica Argentina La Ley tomo 2015 D. Buenos Aires. La Ley. P. 663-676.

Brodsky, J. (2015). El nuevo Código Civil y Comercial de la Nación y la gestación por sustitución: otra oportunidad perdida para una regulación necesaria. En Revista Derecho de Familia. Revista Interdisciplinaria de Doctrina y Jurisprudencia, nro. 68. Buenos Aires. Abeledo Perrot. P. 213-231

Cabrera D. B y Codeglia, L. M. (1995), Responsabilidad por violación del derecho a la identidad, en Alterini, A, A. y López Cabana, R. M. (dirs.), La responsabilidad. Homenaje al profesor Isidoro H. Goldenberg. Abeledo Perrot. Buenos Aires. 1995. p. 115.

Corral Dueñas F. (2003). La filiación derivada de técnicas de reproducción asistida, de Marina Pérez Monge.Revista Critica de Derecho Inmobiliario. Núm. 677., p. 1954. 
Notrica, F.P. Hay que decir que sí a una regulación de gestación por sustitución. Derecho y Ciencias Sociales. Abril 2018. $\mathrm{N}^{\circ}$ 18. (Las familias y el derecho de las familias a dos años de vigencia del Código Civil y Comercial) Pgs 82-98. ISNN 1852-2971. Instituto de Cultura Jurídica y Maestría en Sociología Jurídica. FCJ y S. UNLP

Dickens B. M. (2014). El derecho humano a contar con asistencia médica para fundar una familia, en Zeger F. y Salas S. Bioética, reproducción y familia, Colección de Pensamiento Contemporáneo, Santiago de Chile. Ediciones Universidad Diego Portales. p. 83.

Famá, M. V. (2009). La infertilidad y el acceso a las técnicas de reproducción asistida como un derecho humano, fallo comentado, Cámara Nacional de Apelaciones en lo Civil y Comercial Federal -Sala III-, de fecha 2009-05-19, "B., M. N. y otro c. Dirección de Ayuda Social para Personal del Congreso de la Nación. En Revista Jurídica Argentina La Ley, tomo 2009 D. Buenos Aires. La Ley., pp. 78-85.

Fernández Sessarego, C. (1996). "Daño a la identidad personal”, en Libro de ponencias del Congreso internacional "La persona y el derecho en el fin de siglo". Santa Fe.

Fromm, E. (1967) Psicoanálisis de la sociedad contemporánea. México D.F. Fondo de Cultura Económica..

Gil Domínguez, A (2015). La Gestación por Sustitución como derecho fundamental y derecho humano. Revista de Derecho de Familia y de las Personas, diciembre 2014/5. Buenos Aires. La Ley. pp. 237- 253.

Gil Domínguez, A (2014) La voluntad procreacional como derecho y orden simbólico. Buenos Aires. Ediar.

Guzmán Ávalos, A. y Valdés Martínez M. C. (2017). Voluntad Procreacional, Oñati Sociolegal Series [online], 7 (1), 75-96. Disponible en: https://ssrn.com/abstract=2922064 $(2 / 4 / 2018)$

Herrera, M. y Lamm, E. (2015). Técnicas de reproducción humana asistida, en Bergel S. D et al, Bioética en el nuevo Código civil y Comercial de la Nación. Buenos Aires. La Ley. p. 295-343.

Kemelmajer de Carlucci, A. y Lamm E. (2014). La gestación por sustitución en el Tribunal Supremo de España. Paradoja de la invocación del interés superior del niño para negar sus derechos" (comentario a fallo: Tribunal Supremo de España, sala de lo Civil, pleno D. Ramón y D. César c. Administración General del Estado 2014-02-06). Revista Jurídica Argentina La Ley, tomo 2014-C. Buenos Aires. La Ley. pp. 1-15

Kemelmajer de Carlucci, A.; Lamm, E. y Herrera, Marisa (2013). Gestación por sustitución en Argentina. Inscripción judicial del niño conforme a la regla de la voluntad procreacional, comentario a fallo Juzgado Nacional de 1a Instancia en lo Civil Nro. $86 \sim 2013-06-18 \sim$ N.N. o DGMB M s/ inscripción de nacimiento. Revista Jurídica Argentina La Ley, tomo 2013-D. Buenos Aires. La Ley. pp. 195-206

Kemelmajer de Carlucci, A., Lamm E. y Herrera Marisa (2012). Regulación de la gestación por sustitución. Revista Jurídica Argentina La Ley, tomo 2012-E. Buenos Aires. La Ley. pp.. 960-969

Krasnow, A. N. (2014), Una pareja de lesbianas accede a la cobertura de un tratamiento de procreación asistida por decisión de la justicia. Revista de Derecho de Familia y de las Personas, diciembre 2014. Buenos Aires. La Ley. pp 255-

Lamm, E. (2012).Gestación por sustitución: ni maternidad subrogada ni alquiler de vientres, ed. Observatori de Bioética i Dret, UB, 2012, p. 15.

Mainetti, J. A. (2016). Desarrollo de la bioética en América Latina. Revista Digital Microjuris, Cita online: MJ-DOC-10291-AR | MJD10291. 
Notrica, F.P. Hay que decir que sí a una regulación de gestación por sustitución. Derecho y Ciencias Sociales. Abril 2018. $\mathrm{N}^{\circ}$ 18. (Las familias y el derecho de las familias a dos años de vigencia del Código Civil y Comercial) Pgs 82-98. ISNN 1852-2971. Instituto de Cultura Jurídica y Maestría en Sociología Jurídica. FCJ y S. UNLP

Minyersky, N. (2009). ¿Derecho al hijo/hija? en La familia en el nuevo derecho, Libro Homenaje a Cecilia P. Grosman,. $1^{\circ}$ ed., tomo II. Santa Fe. Rubinzal Culzoni P

Notrica F, Curti, P y Cotado F (2017). La figura de la gestación por sustitución. Revista del Instituto de Ciencias Jurídicas de Puebla, México. Nueva época vol. 11, no. 39. Enero - junio de 2017. P 9.23.

Notrica F., Melon P. y González A. (2016). La gestación por sustitución como una realidad que no puede ser silenciada. Revista Digital Microjuris. Cita online: https://aldiaargentina.microjuris.com/2016/01/08/reflexiones-vinculadas-a-la-gestacion-porsustitucion-y-su-necesidad-de-regulacion-a-traves-de-una-ley-especial/, 1/08/2016.

Sambrizzi, E. A. (2015). Una nueva e improcedente sentencia que admite la maternidad subrogada" -comentario a fallo del Juzgado de Familia $\mathrm{N}^{\circ} 1$ de Mendoza, 2015-07-29, "A. C. G. y otro s/ Medida autosatisfactiva. Revista de Derecho de Familia y de las Personas, diciembre 2015. Cita online: AR/DOC/4031/2015. 